\title{
A study of the applicability to the fatigue of concrete of the Palmgren-Miner partial damage hypothesis*
}

\author{
Ralejs Tepfers, Claes Fridén and Leif Georgsson \\ Contribution by E. W. Bennett \\ University of Leeds, Department of Civil Engineering
}

Dr Tepfers and his colleagues must be thanked for a welcome contribution to the large but as yet otherwise non-existent body of results which, as they say, will be required for an understanding of the cumulative fatigue damage of concrete. It may be of interest to compare their results with those obtained a few years ago at the University of Leeds ${ }^{(1)}$.

These tests differed from those reported in the paper in a number of respects. The specimens were $203 \times 76 \times 76 \mathrm{~mm}$ concrete prisms with a breadth/aggregate size ratio of $76 / 10=7 \cdot 6$ compared with $25 / 8=3 \cdot 1$ for those reported in the paper. The concrete was of higher strength (average cube strength $43 \mathrm{~N} / \mathrm{mm}^{2}$, prism strength $36 \mathrm{~N} / \mathrm{mm}^{2}$ ), but the equation of the $\mathrm{S}-\mathrm{N}$ curve (obtained from eight tests at each of five stress levels) was:

$$
\sigma_{\text {cc max }} / f_{\text {cec }}=0.98-0.0564 \log _{10} N,
$$

which agrees fairly well with the equation 1 of the paper, where $R$ is given the appropriate value of 0.07. The Leeds programme comprised one-step tests similar to the tests reported in the paper, together with a number of two-step and four-step tests, but the two maximum stress levels used were 70 and $80 \%$ of the static strength and were thus a little higher.

Since most of the above differences are not great, it is surprising to find a considerable difference in the results. This is particularly marked in the one-step (i.e. two-stage) tests and is illustrated by Figure I. When repeated loading was first carried out at the lower stress level, the total number of cycles was invariably greater than predicted by the Palmgren-Miner hypothesis, whilst the opposite was true where the first loading was at the higher stress level. Although the results of Dr Tepfers and his

*Pages 123 to 130 of $M C R 100$ colleagues are less decisive, they do in fact support this conclusion, for in Tables 5 and 7, summarizing the tests in which the higher stress was applied first, the mean value of $\log _{10} m$ is negative, showing the Palmgren-Miner hypothesis to be unsafe, whereas

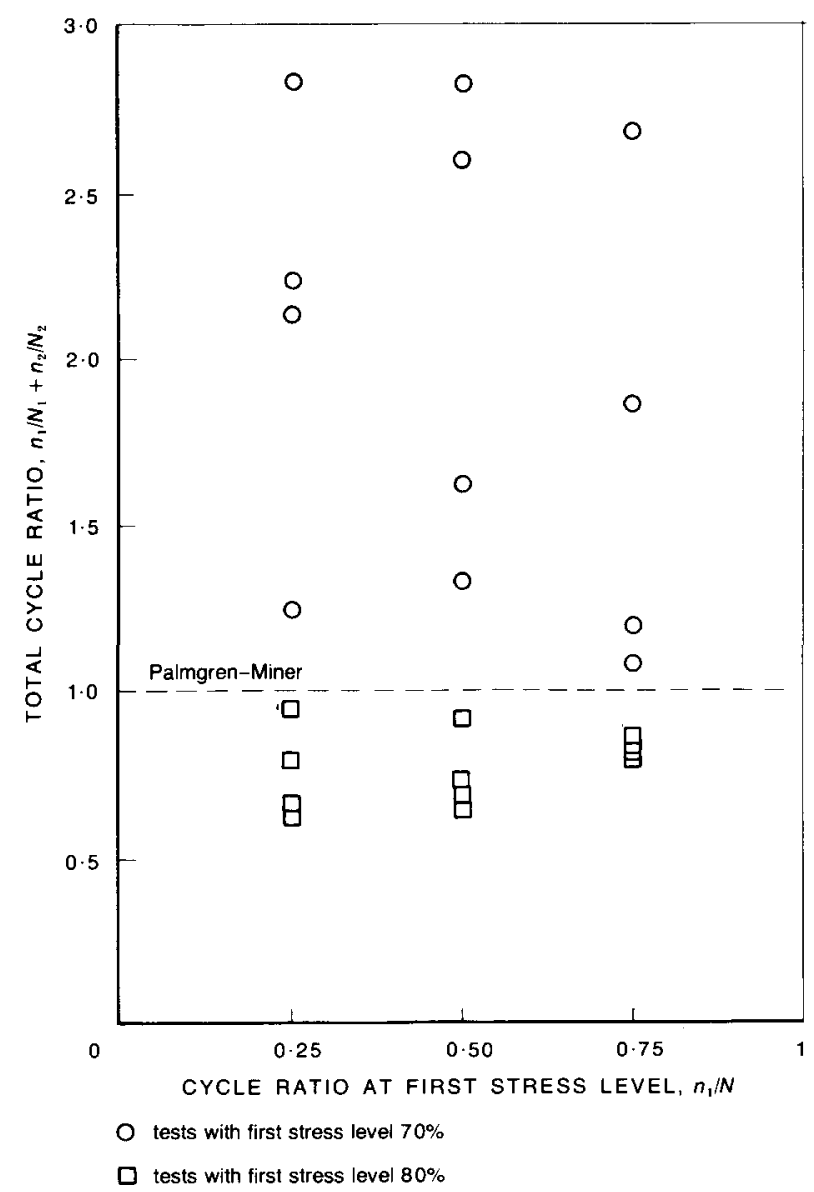

Figure I: Results from the one-step (two-stage) tests at the University of Leeds. 
$\log _{10} m$ is positive in Tables 6 and 8 .

In our two-step (three-stage) tests, the duration of the first two stages was $30 \%$ of the estimated life at that stress level, and the average value of $\Sigma n / N$ was 1.408 (standard deviation 0.519) when the higher stress was applied first and 1.734 (standard deviation 0.792 ) when the lower stress was applied first. In the four-step (five-stage) tests, the duration of the first four stages was $20 \%$ of the estimated life at that stress level and the corresponding values were 1.738 (standard deviation 0.798 ) when the higher stress was applied first and 1.685 (standard deviation 0.819) when the lower stress occurred first.

The impression given by all the results taken together is that the Palmgren-Miner hypothesis is generally conservative, particularly where lower repeated stresses occur first, but that it may occasionally be unsafe if the first repeated stresses are high.

With regard to the tests by Dr Tepfers and his colleagues, whilst in no way minimizing their value, one is unfortunately obliged to comment on the very large scatter of the values of $m[\Sigma(n / N)]$ in Tables 5 to 8 . These vary from 0.1 to $95 \cdot 72$, compared with 0.6 to $2 \cdot 8$ in the Leeds tests. It is probable that this is due to the use of very small specimens and I would suggest that a somewhat larger cylinder would lead to less variable results and would also reduce the number of tests required to establish firm conclusions.

\section{Reply by the authors}

For an acceptable understanding of cumulative partial damage in concrete, as many appropriate test results as possible from different sources are needed. In fatigue tests on concrete, the scatter in the results is considerable at one load level and becomes even worse if the load levels are changed in stages. The contribution to the discussion by Dr Bennett is therefore most welcome.

Firstly we wish to state, that the $S-N$ curves determined in both investigations agree fairly well and equation 1 gives the same results for the stress levels used as the equation given by Dr Bennett. The differences in the results lie in the test results to which the Palmgren-Miner hypothesis is applied and are mainly based on deviations in scatter of the test results.

Before we look at the fatigue test results from stepped load tests, let us look at the existing scatter between results from different sources for determination of an $S-N$ diagram. Equation 1 describes fairly well the $S-N$ diagram for plain concrete. The result becomes better if the constant 0.0634 is replaced by $0 \cdot 0685$. In Figure II, from Tepfers and Kutti ${ }^{(2)}$, is shown the relationship between values of $N$ calculated by using equation 1 and those measured in individual fatigue tests for ordinary concrete in compression. A linear regression analysis has been performed, and the $95 \%$ confidence band has been indicated. The broken line at a slope of $45^{\circ}$ corresponds to complete agreement between equation 1 and tests. Tests with $\sigma_{\text {cemax }} / f_{\text {ccc }} \geqslant 0.8$ have been excluded.

Since there is no technique available at present whereby the $f_{\text {cec }}$ values of the individual specimens can be determined exactly in a non-destructive manner, it is necessary to use during the fatigue tests the mean values of $f_{\mathrm{ccc}}$ determined on test specimens within the same series which have not been subjected to fatigue testing. There are discrepancies of $\sim 5 \%$ from the mean value of the static compressive strength $f_{\text {cce }}$ within the same series. The susceptibility to fatigue is, however, sensitive to such deviations, especially in the case of values of $\sigma_{\mathrm{ccmax} \text { ax }} / f_{\mathrm{ccc}} \geqslant 0.8$. It is seen from Figure III that a change in the value of $\sigma_{\text {cc max }} / f_{\text {cce }}$ from 0.95 to 0.90 , which is equivalent to a deviation of $\sim 5 \%$ between the assumed and true values of $f_{a c c}$, produces an increase of $100 \%$ in the value of $\log _{10} N$ for $R=0$. An increase in the value of $\log _{10} N$ due to an $5 \%$ difference in the value of $f_{\text {ece }}$, when $\sigma_{\text {cc max }} / f_{\text {ccc }}$ is changed from 0.80 to 0.76 , is only $20 \%$.

In Figure II the line for ordinary concrete does not lie within the confidence band, however. This is chiefly due to the fact that the test result population is concentrated and therefore exerts some influence with regard to the direction of the confidence limits.

Closer examination of the test data in Figure I shows that there is a tendency for the values obtained by different researchers to be grouped in different parts of the cluster of points. It may be noted, for instance, that the tests of Bennett and Muir ${ }^{(3)}$ are concentrated below, and those of Antrim and McLaughlin ${ }^{(4)}$ above, the $45^{\circ}$ line in Figure I. However, the test method, apparatus and precision in estimating the static compressive strength $f_{\text {cce }}$ are parameters which cannot be checked easily and which therefore easily give rise to systematic deviations. This applies even more when the loads are stepped.

In Table I, the results obtained from one-step Palmgren-Miner hypothesis tests based on data from four sources are presented. The values by Bennett and Jinawath ${ }^{(1)}$ (Figure I) and Hilsdorf and Kesler ${ }^{(5)}$ have been read from diagrams and the values from Weigler and Freitag ${ }^{(6)}$ have been evaluated from tabulated results by using equation 1 with $0 \cdot 0685$. Weigler and Freitag tested lightweight concrete, whilst Hilsdorf and Kesler made bending tests. Qualitatively the results should show the same tendency, but this is not so. Hilsdorf and Kesler say that over- 


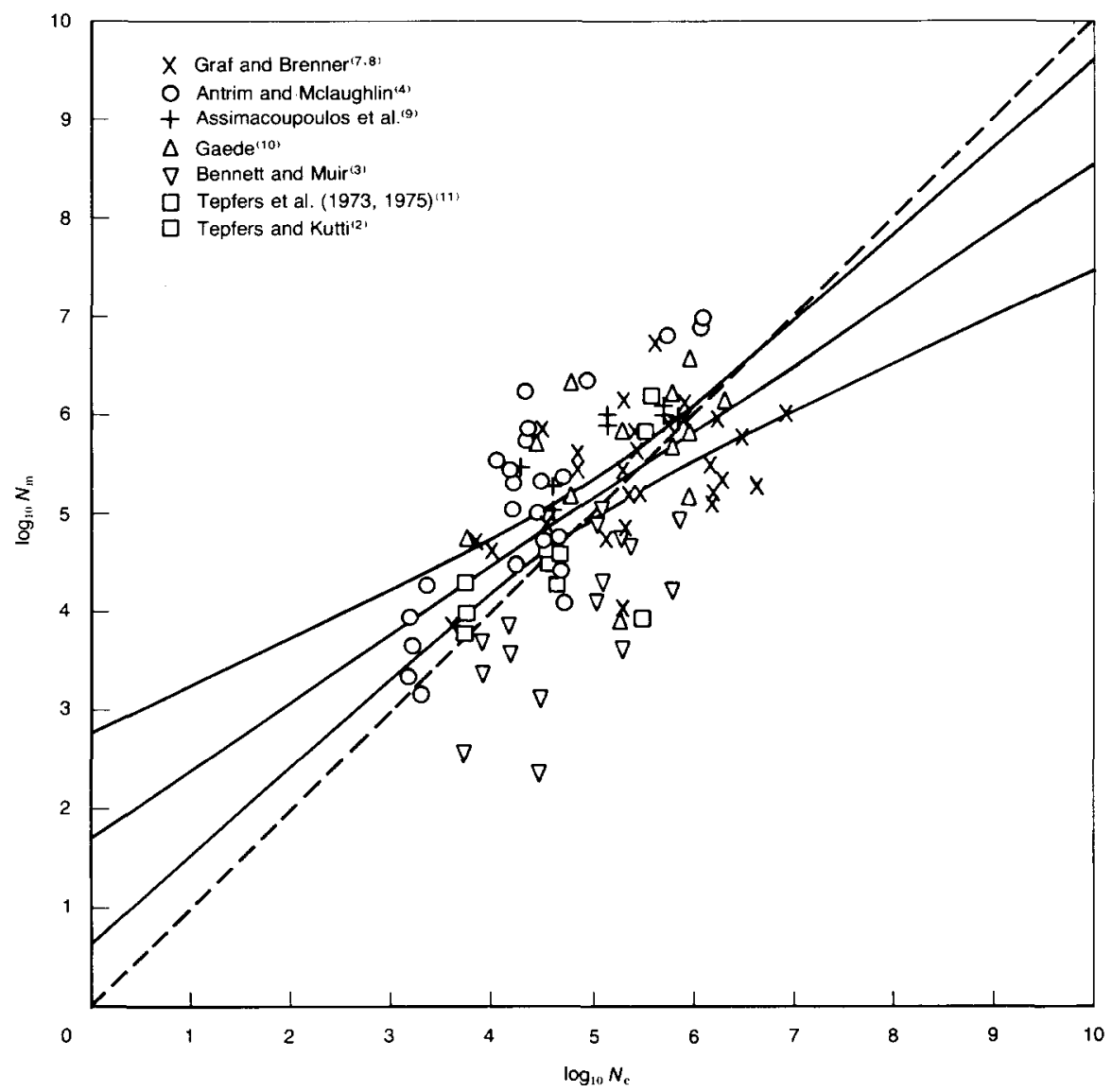

Figure II: Relationship between measured $N_{\mathrm{m}}$ and calculated $N_{\mathrm{c}}$ (number of load pulses at failure of ordinary concrete). $\sigma_{\mathrm{cc} \max } / f_{\mathrm{ccc}}<0.8$. Regression line $\log _{10} N_{\mathrm{m}}=1.681+0.691 \log _{10} N_{\mathrm{c}}$ Coefficient of regression $=0.618$. Number of tests $=107$. $m=0.691 ; C=1.681$.

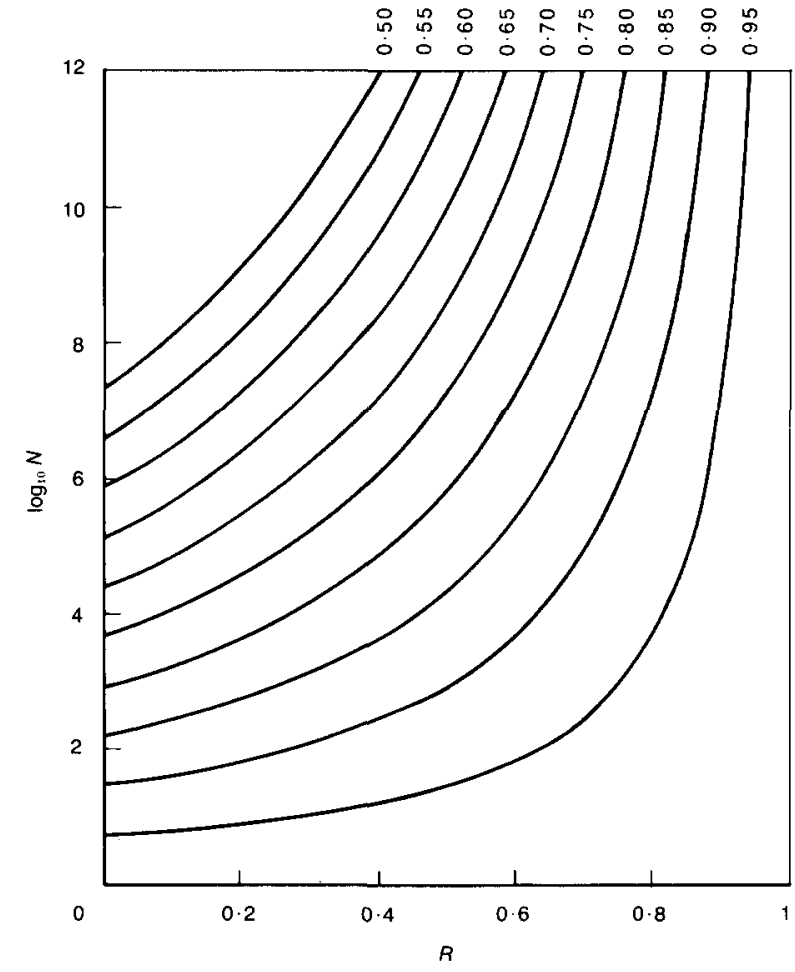

Figure III: Relationship represented by equation 1 with $\beta=0.0685 . \log _{10} N=f(R)$ for different values of $\sigma_{\mathrm{ecmax}} / f_{\mathrm{ccc}}$. loading at the beginning is favourable, whereas Weigler and Freitag say that the order of loads does not matter. Our tests and Bennett and Jinawath's results show the same tendency. Obviously we must be very cautious and just report what we find without extrapolating conclusions.

It is quite true, as Dr Bennett says, that the scatter in results should increase when the specimens are smaller with smaller breadth/aggregate-size ratio. Moreover, a resonance pulsator obviously gives greater scatter than hydraulic loading machines, since Weigler and Freitag and we ourselves used such a machine and have the greatest scatter.

There is, however, one more reason why our test results show greater scatter than those of Bennett and Jinawath. They discontinued their tests after $3 \times 10^{6}$ load cycles. We stopped our tests at different levels, mostly higher than $3 \times 10^{6}$ and up to $20 \times 10^{6} \mathrm{load}$ cycles. If we had stopped our tests at $3 \times 10^{6}$ load cycles, the scatter would be reduced, as becomes obvious from Table I. This actualizes the old questions: "When should one stop a fatigue loading sequence and what should one do with the results of run-out tests?" 
T A B LE 1: Results of one-step Palmgren-Miner hypothesis tests based on data from four sources.

\begin{tabular}{|c|c|c|c|}
\hline Mean $\sum \frac{n_{i}}{N_{i}}$ & $\begin{array}{l}\text { Standard } \\
\text { deviation }\end{array}$ & Mean $\sum \frac{n_{\mathrm{i}}}{N_{\mathrm{i}}}$ & $\begin{array}{l}\text { Standard } \\
\text { deviation }\end{array}$ \\
\hline
\end{tabular}

\section{BENNETT and JINAWATH ${ }^{(1)}$}

Specimen: prism, $76 \times 76 \times 207 \mathrm{~mm}$.

Ordinary concrete, $f_{\mathrm{c} w}=36.0 \mathrm{~N} / \mathrm{mm}^{2}$.

Compression test.

\begin{tabular}{l|l|l|l}
\hline 0.78 & 0.11 & 1.97 & 0.67 \\
\hline
\end{tabular}

TEPFERS, FRIDÉN and GEORGSSON

Specimen: cylinder, $f=25 \mathrm{~mm}, h=50 \mathrm{~mm}$.

Ordinary concrete, $f_{\mathrm{ccc}}=20 \cdot 8 \mathrm{~N} / \mathrm{mm}^{2}$.

Compression test.

\begin{tabular}{|c|c|}
\hline $3 \cdot 1$ & 3.87 \\
\hline
\end{tabular}

If the test had been discontinued after $3 \times 10^{6}$ load repetitions:

$$
1.00
$$

$$
0 \cdot 94
$$

$$
9 \cdot 65
$$

\section{WEIGLER and FREITAG ${ }^{(6)}$}

Specimen: cylinder, $\phi=50 \mathrm{~mm}, h=100 \mathrm{~mm}$.

Lightweight concrete, $f_{\text {ece }}=45 \cdot 2 \mathrm{~N} / \mathrm{mm}^{2}$.

Compression test.

\begin{tabular}{l|l|l|l}
\hline 3.28 & 5.55 & $\geqslant 2 \cdot 10$ & 4.36 \\
\hline
\end{tabular}

\section{HILSDORF and KESLER ${ }^{(5)}$}

Specimen: prism, $150 \times 150 \times 1500 \mathrm{~mm}$.

Ordinary concrete, modulus of rupture $\sim 4.4 \mathrm{~N} / \mathrm{mm}^{2}$ and

\begin{tabular}{|c|c|c|c|c|}
\hline $1 \cdot 282$ & 0.574 & $>$ & 0.710 & 0.274 \\
\hline
\end{tabular}
$f_{\text {cec }}-33 \mathrm{~N} / \mathrm{mm}^{2}$ estimated from water/cement ratio of 0.52 Bending test.

\section{REFERENCES}

1. BENNETT, E. W. and InAwath, P. Compressive strength of concrete under repeated loading of varying intensity. Conference on the Service Life of Supporting Structures in Concrete and Panel Buildings, Bmo, October 1975. Czechoslovak Scientific and Technical Society.

2. TEPFERS, R. and KUTTI, T. Tryckutmattningshållfasthet för betong och läattballastbetong. (The compressive fatigue strength of ordinary and lightweight concrete.) Gothenburg. Chalmers University of Technology, Division of Building Technology, 1977. pp. 53. Rapport 77:5.

3. BENNETT, E. W. and MUIR, S. E. StJ Some fatigue tests of high strength concrete in axial compression. Magazine of Concrete Research. Vol. 19, No. 59. June 1967. pp. 113-117.

4. Antrim, J. DE C. and Mclaughlin, J. F. Fatigue study of airentrained concrete. Journal of the American Concrete Institute. Proceedings Vol. 55. 1958-1959. pp. 1173-1182.

5. HILSDORF, H. K. and Kesler, C. E. Fatigue strength of concrete under varying flexural stresses. Joumal of the American Concrete Institute. Proceedings Vol. 63, 1966. pp. 1059-1075.

6. WEIGler, H. and freitag, W. Dauerschwell- und Betriebsfestigkeit von Konstruktions-Leichtbeton. (Fatigue and working strength of structural lightweight concrete.) Berlin, Wilhelm Ernst und Sohn, 1975. Deutscher Ausschuss für Stahlbeton. Heft 247. pp. 45-74.

7. GRAF, o. and BRENnER, E. Versuche zur Ermittlung der Wiederstandsfahigkeit von Beton gegen of tmals wiederholte Druckbelastung. Berlin, Wilhelm Ernst und Sohn, 1934. Deutscher Ausschuss für Eisenbeton. Heft 76. pp 1-13.

8. GRAF, O. and BRENNER, E. Versuche zur Ermittlung der Wiederstandsfahigkeit von Beton gegen of tmals wiederholte Druckbelastung. Berlin, Wilhelm Ernst und Sohn, 1936. Deutscher Ausschuss für Eisenbeton. Heft 83. pp. 1-12.

9. assimacopoulos, B. M., WARNER, R. E. and EKBERG, C. E. High speed fatigue tests on small specimens of plain concrete. Journal of the American Concrete Institute. Proceedings Vol. 56, No. 2. September 1959. pp. 53-70.

10. GAEDE, K. Versuche uber die Festigkeit und die Verformung von Beton bei Druck-Schwellbeanspruchung. (The strength and deformation of concrete subjected to compressive pulsating load.) Berlin, Wilhelm Ernst und Sohn, 1962. Deutscher Ausschuss für Stahlbeton. Heft 144. pp. 48.

11. TEPFERS, R., GörLIN, J. and SAMUELSSON, T. Concrete subjected to pulsating load and pulsating deformation of different pulse waveforms. Nordisk Betong. No. 4. 1973. pp. 27-36. 